Journal of Teacher Education for Sustainability, vol. 22, no. 2, pp. 140-152, 2020

\title{
Environmental Education Competency: Enhancing the Work of Teachers
}

\author{
Yodsaphon Wanchana, Pram Inprom and Wee Rawang \\ Faculty of Social Sciences and Humanities, Mahidol University, \\ Nakhonpathom, Thailand \\ Art-ong Jumsai Na Ayudhya \\ Sathya Sai School, Lopburi, Thailand
}

\begin{abstract}
The research into the environmental education competency of secondary school teachers was conducted using mixed research methods. The data were collected using the questionnaire and the structured interview. The teachers of eco-schools completed the questionnaire and teacher advisors as well as mentor teachers of the eco-school project participated in the structured interview. The research findings revealed that most respondents had a moderate level of environmental education competency that involved six aspects: knowledge of the environment, basic understanding of the environment, responsibility for the environmental education of professional teachers, planning and practice with regard to the environmental education, promoting learning about the environmental education and evaluation of the environmental education. The approaches to enhance the environmental education competency of secondary school teachers should involve multidisciplinary instruction learning, community-based learning, project-based learning, happy teaching and learning, and holistic learning management.
\end{abstract}

Keywords: Environmental education, multidisciplinary instruction learning, communitybased learning, project-based learning, holistic learning management

\section{Introduction}

Environmental education (EE) is a tool to sustain development success. Chatzifotiou (2006) reported the impact of environmental education on primary teachers in England and discussed sustainable development in this field. Since environmental educators are considered one of the main actors in sustainable development, the article aims to show the interaction among environmental education, national curriculum and primary teachers. The conflict between the study of sustainable development and environmental education in the national curriculum seems to be both parallel and convergent. This article also describes some aspects of education for sustainable development based upon environmental education. Álvarez-García, Sureda-Negre, and Comas-Forgas (2015, pp. 7285 ) evaluated and analyzed the relationship of environmental education. 
The success of the environmental education process requires a standard teaching in all systems of school management that the environmental education is the policy, which lacks concrete and clear methods and practices. There is a need to recognize the unsustainability as a trend in global development known as Anthropocene that has been identified by studying human nature relationships (Salite, 2015; Salite et al., 2019). The teachers lack understanding and skills in environmental education. Teachers have many duties, lack the cooperation of the school system, and lack the knowledge of resources for learning from nature and environment to promote the learning of students. To find the ways for developing and managing the environment in a changing world, in teaching and the curriculum activities of the basic education the children have the opportunity to really practice, learn from some real experiences and experience more activities than in the past. Teachers have a lot of teaching and do not have enough time to find the information, as well as most teachers do not graduate in the field of teaching, although vocational education and higher education are interrelated and many are able to create the curriculum themselves. Various curricula lack environmental integration and students lack awareness of the energy and environment, including the advisor who lacks relevant information on the current situation (Salite et al., 2016).

According to the research conducted by the Department of Environmental Quality Promotion (the Ministry of Natural Resources and Environment) in 2015, the problem of environmental education in schools is related to teachers because they create learning platforms for their classrooms. The development of the environmental education process is successful when all personnel in the school see the importance of working with the community. They look at the development of environmental education processes to link communities and schools, which cannot be separated because the process of raising awareness for children does not only happen in school. The children are the medium of linking environmental knowledge in school to the community and this results in concrete objectives to solve environmental problems and achieve sustainability in a community. Therefore, the present research examines the current situation of environmental education competency of secondary school teachers and investigates the ways how the teachers should improve their environmental education competency.

\section{Research Methodology}

Both quantitative and qualitative research methods were used to study the environmental education competency of teachers in secondary schools. The research examined secondary school teachers from 6 regions of Thailand. Questionnaires were used to collect data from 408 teachers involved in environmental activities and projects for secondary schools. The authors also conducted in-depth structured interviews to find out opinions on the environmental education competency from 19 mentor teachers from nine eco-schools, and the Director of the Environmental Education Sector, Department of Environmental Quality Promotion, Ministry of Natural Resources and Environment.

\section{Research Results and Discussion}

The research findings revealed that the teachers were largely female $(73.28 \%)$, over 50 years old for most of the professional level teachers $(35.54 \%)$, and had a Bachelor degree $(65.69 \%)$. Science teachers $(44.36 \%$ ) participated in activities/environ- 
mental training projects 1-2 times in the academic year or once per semester. The 20 participants of the in-depth interview were 19 secondary school teachers from 9 pilot schools of environmental education for sustainable development (eco-school), and the Director of the Environmental Education Sector, the Department of Environmental Quality Promotion, Ministry of Natural Resources and Environment.

Competency may be referred to the "ability, potentiality, performance, or desirable behavior" (Arporn Puvitayaphan, 2018, pp. 13-17). It has three components: 1) knowledge and understanding that refer to the recognition of thinking, principle, process, the stages of each subject, which require the pursuit of knowledge such as studying in schools, classroom training, reading, asking knowledgeable people, teaching; and study trips; 2) skills that are the actions or expressions, which are frequently practiced; and 3) attributes that refer to the mind of each person and the inner power that fuels inner growth or implantation developed from childhood such as patience, honesty, working commitment, conscious mind, ethics, positive thinking, circumspection, and responsibility, etc.

The characteristic of the environmental education competency has shown the ability of secondary school teachers to integrate environmental education with a variety of learning areas for the students in eco-school. The environmental education competency consists of six aspects (see Table 1).

Table 1

The EE Competency of Secondary Sschool Teachers

\begin{tabular}{lccc}
\hline Environmental education competency & $\overline{\mathrm{x}}$ & S.D. & Level \\
\hline 1. Knowledge of the environment & 3.51 & 0.73 & High \\
\hline $\begin{array}{l}\text { 2. Basic understanding of the environment } \\
\text { 3. Responsibility for the environmental education of } \\
\text { professional teachers }\end{array}$ & 3.46 & 0.73 & Moderate \\
\hline $\begin{array}{l}\text { 4. Planning and practice with regard to the environmental } \\
\text { education }\end{array}$ & 3.49 & 0.83 & Moderate \\
\hline $\begin{array}{l}\text { 5. Promoting learning about the environmental education } \\
\text { 6. Evaluation of the environmental education }\end{array}$ & 3.48 & 0.75 & Moderate \\
\hline Average & 3.33 & 0.76 & Moderate \\
\hline
\end{tabular}

1. Knowledge of the environment. Most respondents could select the sources of environmental education, which were correct and reliable sources of learning. They had the knowledge and understanding of the historical areas of biology and local culture, accompanied by a variety of biological issues. They had the knowledge and understanding of biological change, accompanied by the planning and management of the environmental issues that were linked to civil rights and responsibility. Thus, an approach was developed with regard to these environmental issues. After respondents researched, analyzed, evaluated the frame and cause, and the subsequent approach, they researched and evaluated various types of choice for solving problems. Accordingly, the total average of environmental education competency was high.

2. Basis understanding of the environment. Most respondents understood the goal, objectives, and the basis of environmental education, and knew about the departments/organizations related to the environmental education. They could also explain 
the current state of environmental education. Accordingly, the total average of environmental education competency was moderate.

3. Responsibility for the environmental education of professional teachers. Most respondents used the teaching method that determined real practice, teaching materials and instructional media to enhance student's awareness of environmental education. New approaches that supported their beliefs and self-assessment to create plans/ activities for their professional advancement were developed in the past, present and future. By following their explanations and examples, one could compare the difference between propaganda and education. They respectfully presented the academic work in committee meetings for a variety of activities in communication with the local community. They linked inquiry-based approaches to the academic standard of the provincial and national levels. Accordingly, the total average of environmental education competency was moderate.

4. Planning and practice with regard to the environmental education. Most respondents supported and promoted environmental education, and chose the appropriate technologies and instruments for teaching. They used the appropriate environmental education with teaching methods for natural subjects, and chose the instrumental media from community, organization, company, sectors, professional training curriculum development, and/or internet for the learners appropriately. They analyzed the environmental problems of the learners and used the contents of teaching methods appropriately. They understood the concept of content knowledge and skills, the order of learner's development and the skills consistent with the curriculum, which followed the integration of environmental education subjects to link with the main curriculum, sub-curriculum, and the school mission. Subsequently, they provided the field experience to link the contents with the learner's environment, and made the appropriate teaching methods consistent with a variety of learners, which considered the various differences of cultural and social background, economy, age, educational level, special needs, and learning abilities. They evaluated the basic environmental curriculum, which should lead to life-long learning of the learners. Accordingly, the total average of environmental education competency was moderate.

5. Promoting learning about the environmental education. Most respondents took the advantage of appropriate time to teach by being flexible and open-minded in asking and answering questions of the learners. They succeeded in inducing them to learn and provide investigative experience for the learner's development. Moreover, they could stimulate and promote an interesting atmosphere among learners. Accordingly, the total average of environmental education competency was moderate.

6. Evaluation of the environmental education. Most respondents could apply the evaluation and/or assessment to improve teaching. They used evaluation to determine the efficiency of teaching methods. They used at least two methods to evaluate the knowledge, emotions and skills of the learners. It consisted of determining the teaching objectives and the learner's expectations. They also used the methods to assess planning in order to improve the environmental education curriculum. Accordingly, the total average of environmental education competency was moderate.

The Committee of the North American Association of Environmental Education (NAAEE) has determined the core competency for students in the Graduate Diploma for Teacher Professionals of Environmental Education, which has 6 instances of frame- 
work development. Likewise, Yavetza, Goldmanb, and Pe'erc (2014, pp. 354-371) studied the trainer teacher's perceptions about the environment and subjects concerned. The environment not only involved ecological characteristics, but also structural concepts (construct) of cultural construct, society, and politics as well. The trainer teachers accepted the importance of teaching environmental issues in the future. These trainer teachers did not show sufficient understanding of the environmental concept, i.e., humans were not seen as part of the environment or the environment was not understood as a complex network of interactions among people. This concept included the idea that humans comprised various ecological systems in nature as well. The understanding of the trainer teachers was still at a basic level, which indicated the need to improve the curriculum of the professional teachers in the environmental education. The nature of the student's perception of the environment related to their fields was a starting point for the change. The student's explanations were relevant to the structural concepts of "environment". The understanding of the environment was an object that was not linked to a holistic understanding of the human relationship and the various interventions and a dualistic view of a conflict between natural and man-made systems. Thus, the structural concepts should be considered in designing or planning a curriculum with a view to sustainable development.

The results of the interviewing secondary school teachers about the environmental education competency could be summarized according to five categories:

Item 1: Problem, situation, and activities/ environmental education projects in the environmental education for sustainable development in schools: eco-schools. There was framework management taking into account four missions:

- The environmental policy and structural management as a mission, which was relevant for school administrators who determined the policy, vision, and clear environmental education management structure leading to practice in schools and community. It was observed that many eco-schools could not operate in accordance with the policy of environmental education schools for sustainable development, because the school administrators lacked the understanding of environmental education. Therefore, it was policy change management, which did not provide for the environmental education management in schools.

- Learning process was focused on teacher development and promoted in various environment education learning systems by focusing on learning management. It was linked to the issues of natural resources and local environment based on the concept of process learning "ABOUT" the learning environment "IN" that environment and learning "FOR" the environment (Learning ABOUTIN-FOR ENVIRONMENT) by using problem-based learning instead of coaching. The coaching process was not successful as employed by professors at the university. The authors of the study observed that teachers did not understand the goals of environmental education, which focused on developing citizens for sustainable development, so it was needed to promote the competency of social studies teachers. It could enable the teachers to provide the environmental education activities without feeling that environmental education activities were the load of the work of learning management. 
- Natural and environmental management in schools was promoted by the teachers who applied activities for outdoor learning by using resource centers in schools and locally instead of strictly classroom. The authors of the study observed that most learning activities were taught in the classroom only. The learning activities were a result of static curriculum content over time. There was a photo monoculture that it could not take the content from the curriculum into the integration of learning activities.

- Participation and networking of environmental education would provide the opportunities for parents, communities, and other departments or various organizations to participate and support the school management that created the learning resources within the school by focusing on the participation.

Item 2: Factors promoting environmental education in schools:

- The focus was on the participation by building the resource center within the school. "One Classroom - One Resource Center" in the classroom where teachers served as mentors.

- Teachers must know their own communities, and that their learning was about geography, climate, ecological characteristics, geography and ecology of the area, using the benefit of the resources in the community, and the impact of the environment on the community.

- The school administrators must promote and support curriculum development that needs to be flexible and consistent with the school policy. It should include the participation of the administrators and teachers, who have to conduct a SWOT analysis together to evaluate the strengths and weaknesses of the school in order to determine whether the school is a distinctive part of the environment. Thus, the direction of a school policy must promote and support the students to have the morals based on the philosophy of sufficiency economy through the environmental education process, etc.

Item 3: Promoting secondary school teacher's competency in the environmental education would enable the schools to be successful in integrating important contents of the environmental education into the curriculum. All teachers, administrators, and supervisors need to meet together, critically examine the issues and vote. The administration should initiate the PDCA (Plan-Do-Check-Act) process. The administrators would need to perform a SWOT analysis in order to find out the distinctive points.

The curriculum developed on the basis of the PDCA process could be adjusted all the time and made flexible. In addition, environmental education curriculum focuses on using the process and it will be flexible following the interests of children because each year the interests of children are different. Thus, the learning process will enable the children to learn something that they want to know, by discovering knowledge themselves. Accordingly, there is a need to have a flexible curriculum for children to learn what they want to know.

Item 4: Important components to develop secondary school teacher's competency:

- Teachers need to understand environmental education integrated methods and use them in accordance with the standards of the Office of National Education Standards and Quality Assessment and the Office of the Basic Education Commission. 
- Teachers must know the seven stages of environmental education. This was one of the problem situations to bring the school to the community or bring the community into the school. The seven stages of environmental education process are the following: to choose a situation or a learning issue, to provide a knowledge base, to analyze the linked relationships, to study the options and make various choices, to design the planning, train and practice, and to exchange learning. This way, teachers must plan their PDCA.

- Community-based learning. It involves the knowledge of the community, geography, climate, ecological characteristics and ecology of the area, benefits of resources in the ecology, and the impact of the problem on the community.

- Problem-based learning involves the examination of problems of community and uses these problems to set up learning opportunities for a child. The teacher would know what children were interested in after letting them explore problems and analyze the relationships. They would learn the community situation: what was happening, how problems would be solved, and analyze alternatives. This would be in accordance with the children planning the real practice and sharing their learning to solve the problem affecting their communities.

- Integration of environmental education into various subjects. It focuses on using process and flexibility according to the interests of different learners because what students are interested in and want to learn is the result of their own discovery. Thus, learning management must be flexible for the learners to learn in the area and solve the problem themselves.

- The evaluation of learning in the subjects is the result of the learning process. Learners would be tested without knowing it, and teachers would test the learners through authentic assessments.

Therefore, the model of environmental education competency development for secondary school teachers should consist of three concepts: Integrated Instructions (focusing on the integration of various learning areas into environmental education), Community-Based Learning (focusing on the use of the environmental education for solving environmental problems in the community) and Project-Based Learning (focusing on writing the plans or the projects to solve environmental problems). The focus is to promote student's consciousness of the environment and follow environmental conservation practices in their communities. The quality of environmental education should be evaluated by the experts and its efficiency should be evaluated by actual performance, thus enabling students to get involved in both integrated learning and community development (Rawang, 2020, pp. 46-52). The important approaches to enhance the environmental education competency of secondary school teachers should consist of multidisciplinary instructional learning, community-based learning, project-based learning, happy teaching and learning, and holistic learning management.

\section{Multidisciplinary Instruction Learning}

The research findings revealed that environmental education learning management needs to be integrated with multidisciplinary instruction and the teachers should meet together and discuss the subjects. Environmental issues in the community should have 
the Theme of Conceptual Framework of integrated learning management. Then, each teacher, who is responsible for different subjects, will decide on which aspects to focus in the integrated learning management. Teachers will be able to independently choose their learning management and how to use the authentic assessments. After the students finish the subject, teachers should inform of the results of integrated learning during meetings and they should together seek ways to improve or develop their subjects through more effective learning management. Integrated teaching is linked to many subjects and is not a subject itself, but it is involved in teaching methods. If the teacher is separated by different fields of learning, then the other subjects are not taught. In addition, the environment in the classroom, for example, arranging chairs in rows or circles also affects learning of the students (White, 1981, p. 16). This opens up an opportunity to allow students and teachers to cooperate in order to make the learning process interesting and let the students study in small groups or individually. The curriculum of integration needs to arrange the appropriate time to meet different student's interests and grant more freedom and creativity as a basis of knowledge. In addition, the teachers can find the students who have the capability and interests, including the students who have the opportunity to develop their skills (Blishen, 1969, p. 27; Heasly et al., 2020). The teaching process, which combines the content of the subjects into a unit of study as well as the student's activities, can solve problems in appropriate situations (Hopkins, 1973, pp. 21-22).

\section{Community-Based Learning}

The environmental education learning management for secondary school learners should incorporate community-based learning, within which the learners develop an understanding of the quality of life and the quality of environment in their community. Thus, the real environmental problems must be managed according to the concept of integrated learning, which is important for successful outcomes. The place-based curriculum represents the ultimate goals of education that meaningfully connect local knowledge and modern knowledge together in order to empower the students and community in a sustainable way (Jatuporn \& Wattanaton, 2015, pp. 83-111). In terms of highly effective pedagogy, community-based learning should be used to enable learners to acquire $21^{\text {st }}$ century skills. This is a teaching strategy that links the contents of the lessons to the community through the integration of knowledge in many subjects, the examination of real-life problems and its proximity to the community and the environment of the learner, thus focusing on thinking skills, problem-solving and learning through handson experience. The evaluation is an authentic assessment with the involvement of relevant people. It should be noted that successful implementation of community-based learning depends on the teacher who needs to clearly specify learning strategies and learning outcomes. Learners learn from their actions in the community through collaboration among the representatives of the educational network, the community and the learners (Rittikoop, 2018, pp. 179-189). However, community-based learning is a pedagogical approach, which has tremendous potential to produce better citizens. The success of a community-based learning experience relies on considering a number of factors, such as thorough planning, critical reflection, effective project management, assessment and effective project evaluation (Bedri, Ruairí de Fréin, \& Dowling, 2017, p. 1). 


\section{Project-Based Learning}

Project-based learning is a system approach to develop the learner's intelligence. It is the learning model based on the concepts of constructivism that enables students to create new knowledge from real problems in the world, which is the learning context. The learning process focuses on the students, i.e., to make them develop thinking skills, analytical and problem-solving skills, including knowledge in their subjects that enables the students to practice methods and solve problems themselves. Project-based learning is an active student-centered form of instruction, which is characterized by student's autonomy, constructive investigations, goal-setting, collaboration, communication and reflection within real-world practices (Kokotsaki, Menzies, \& Wiggins, 2016, pp. 267277). It was found that after using a set of guided activities, the students had higher problem-solving skills than before the experiment with a statistical significance at .05 level (Srisaiphet, 2016, pp. 61-68). Project-based learning is the process that requires understanding and problem-solving. This process encourages the student to practice in many ways, such as critical thinking, analytical thinking and synthesis thinking (Suwannoi, 2016, pp. 1-10).

\section{Happy Teaching and Learning}

The environmental education for secondary school teachers consists of five steps: analyzing the educational policy, studying the community environmental problems, designing the environmental project, identifying the standard of learning, and performing the integrated lesson plans. These five steps will be implemented through happy teaching and learning to teachers, students, and community, for this learning is to link real-life problems to the learning process. The Happy School Criteria should consist of the three categories: people, process, and place (UNESCO, 2016, pp.12-15). People refer to friendships and relationships in the school community, positive teacher attitudes and attributes, and positive and collaborative values and practices. Process encompasses teaching and learning methodologies that can enhance learner's sense of well-being as having reasonable and fair workload, learner freedom, creativity and engagement, and useful, relevant and engaging learning content. Place refers to contextual factors, both in terms of the physical environment and the school atmosphere as having a warm and friendly learning environment, free from bullying, with school vision and leadership, and open and green learning and playing spaces.

It should be emphasized that happiness and well-being are increasingly recognized as a global priority, including in the new international development agenda. This has followed from the recognition that the pressure of today's ever-changing world, including the changing nature of work, may lead people to become unhappy. Therefore, education systems need to adapt and shift towards prioritizing 'non-academic' domains of learning. At the global, national and education levels, efforts have been made to measure wellbeing and the skills and competencies that enhance happiness and well-being. This is demonstrated by the seventh target of SDG4, which is dedicated to promoting the skills and competencies that are reflected in concepts such as Learning to Be and Learning to Live Together as well as Education for Sustainable Development and Global Citizenship Education (UNESCO, 2016, p. 35). 


\section{Holistic Learning Management}

Holistic learning management is related to UNESCO (2020, pp. 16-17); for a radical reconfiguration of our paradigms, it is necessary to confront the complexity of our time with a holistic perspective and to find creative solutions to achieve sustainable development. In this context, 'learning to become' is the new perspective and it will require experimental research through immersive practices and experiences of active listening to foster the growth of self-awareness and awareness of the whole. The meditative practices required to gain this awareness are contained in the heritage of certain cultures, some of which are not completely foreign to the Western world. Nowadays, meditative practices can serve as a tool in formal educational systems to strengthen the necessary skills, to root the individual in the journey, to navigate emotions, perceptions and understanding of the global challenges as a whole as well as to promote the awareness of the choices available for oneself and for the whole.

The research findings revealed that Sathyasai School, Lopburi province taught systematically using knowledge-integrated teaching to develop the students, school, community, and environment. Sathya Sai School curriculum is based on the Education Human Values Program, which consists of the human values such as truth, right behavior, peace, love, and non-violence (Art-ong Jumsai Na Ayudhya and Loraine Burrows, 1991). It is the principle of the school to build the character of the children. The human values like truth, honesty, love, loyalty, sharing, compassion, courage, and determination are imparted in day-to-day functioning. The weekends are devoted to activities like planting trees or planting rice seedlings, to inculcate environmental awareness. In the process, the children are taught to develop their commitment to the society. The teacher must be creating inspirational teaching; teachers must be good role models, who develop the human values within the learners, integrate human values in various subjects and activities, and use collaborative learning. Then, every facet of teaching activities, be it living, studying, or playing, places an emphasis on teamwork rather than on individual achievement (Art-ong Jumsai Na Ayudhya, 2007).

Mahidol University has been trying to develop "an ideal campus" for providing favorable environment for learning and having physical structure, which is in harmony with society and environment. The sustainable policy consists of five aspects: land use development, landscape system development, in-campus traffic circulation development, infrastructure service system development, and building and construction control. The environmental, economic, and social impacts of a green office were consistent with sustainable development goals (SDGs) (Aroonsrimorakot, Laiphrakpam, \& Paisantanakij, 2020, pp. 164-177; Pipere, Veisson, \& Salìte, 2015). Students have to develop the skills they need to overcome global challenges, explore new opportunities, and grow as globally competent citizens. We focus on student centered and active learning so that all graduates have the professional skills they need for their work, as well as creativity and adaptability necessary for the changing world.

\section{Conclusions}

The environmental education competency of secondary school teachers involves six aspects: knowledge of the the environment, basic understanding of the environment, responsibility for the environmental education of professional teachers, planning and 
practice with regard to the environmental education, promoting learning of the environmental education, and evaluation of the environmental education.

The approaches to enhance the environmental education competency of secondary schools teachers should focus on promoting student's awareness of the environment, feeling love for the environment before environmental conservation in their communities. The approaches should involve multidisciplinary instruction learning, community-based learning, project-based learning, happy teaching and learning, and holistic learning management.

However, the recommendation of the practical research is to support student's participation in the environmental community management through integrated learning. This means getting community support, and thus local organizations should be part of an integrated learning about environmental education continuously. The administrator should evaluate the integrated learning performance of teachers to determine the school level policy, schools should be understood as having a shared vision. Integrated activities should be used in the environmental education in response to the Ministry of Education policy about "Moderate Class, More Knowledge", giving the students to practice "learning by doing than learning in the classroom". The constructive punishment should be used as creative punishment for environmental education activities, environmental education activities should be applied to local culture, and environmental school management should focus on supporting the environment. Student activities should be designed through the "one classroom one project/ or one classroom one goodness/ or one classroom one product", concepts. Loving the environment through teachers and students involves opening teacher opportunities to lead the classroom through the concept of neo-humanism for environmental awareness, and it should be a standard for the environmental education in the teaching profession.

Moreover, the recommendation for further research may involve an environmental youth leader development process, master-teacher creation process, various forms of integrated learning, such as infusion, and paralleled instruction, supporting ways or promoting administrators to use the knowledge in order to determine the policy, methods of extending integrated learning research for secondary school teachers to other educational levels, such as kindergarten, primary school, and vocational college, and applying teacher-directed roles to support student's knowledge.

\section{References}

Art-Ong Jumsai Na Ayudhya (2007). Moral above knowledge, integrated teaching models, value of being humans. Bangkok: V.T.C. Communication Ltd., Part.

Art-ong Jumsai Na Ayudhya, \& Burrows, L. (1991). Sathya Sai education in human values handbook for teachers. Sathya Sai Foundation of Thailand.

Álvarez-García, O., Sureda-Negre, J., \& Comas-Forgas, R. (2015). Environmental education in pre-service teacher training: A literature review of existing evidence. Journal of Teacher Education for Sustainability, 17(1), 72-85.

Aroonsrimorakot, S., Laiphrakpam, M., \& Paisantanakij, W. (2020). Impacts of green office projects in Thailand: An evaluation consistent with sustainable development goals (SDGs). Journal of Sustainable Development, 13(4), 164-177.

Bedri, Z., Ruairí de Fréin, \& Dowling, G. (2017). Community-based learning: A primer. Irish Journal of Academic Practice, 6(1), 1, 1-26. 
Blishen, E. (1969). This right soft lot. London: Thames \& Hudson.

Chatzifotiou, A. (2006). Environmental education, national curriculum and primary school teachers. Findings of a research study in England and possible implications upon education for sustainable development. The Curriculum Journal, 17(4), 367381.

Department of Environmental Quality Promotion (2015). Decoding environmental education in schools, research. Thailand: Ministry of Natural Resources and Environment.

Grabovska, R., \& Grabowski, J. (2009). Implementing the United Nations Decade on Education for Sustainable Development in Latvian Higher Education. Journal of Teacher Education for Sustainability, 11(1), 8-30.

Heasly, B., Iliško, Dz., Salìte, I., \& Lindner, J. (2020). The value of process and pedagogy through the sustainability prism. Discourse and Communication for Sustainable Education, 11(2), 1-4.

Hopkins, C. (1973). Integration, its meaning and application. New York: Appleton Century Company Inc.

Jatuporn, O., \& Watthanathorn, A. (2015). Place-based education: The development of good citizenship in youth based on community contexts. Songklanakarin Journal of Social Science and Humanities (SJSH), 21(1), 83-111.

Kokotsaki, D., Menzies, V., \& Wiggins, A. (2016). Project-based learning: A review of the literature. Improving Schools, 19(3), 267-277. Retrieved from https://doi.org/ $10.1177 / 1365480216659733$

Mahidol University. (2020). Sustainability Policies. Retrieved from https://www.mahidol. ac.th/sustainable/

NAAEE. (n.d.). The Core Competencies for Certification Programs. Retrieved from http://www.naaee.net/files/core_competencies.pdf

Pipere, A., Veisson, M, \& Salite, I. (2015). Developing research in teacher education for sustainability: UN DESD via the Journal of Teacher Education for Sustainability. Journal of Teacher Education for Sustainability, 17(2), 5-43.

Puvitayaphan, A. (2018). Competency assessment tool. Retrieved from https://www.hrcenter.co.th/?m=book_detail\&id=12724

Rawang, W. (2020). Registered intellectual property on systematic sciences of environmental education: As the sustainable development process-SDP. Nakhonpathom: Mahidol University.

Rittikoop, W. (2018). Community-based learning: Effective pedagogy strategies for teachers in the $21^{\text {st }}$ Century. Graduate School Journal, 11(3), 179-189.

Salite, I. (2015). Searching for sustainability in teacher education and educational research: Experiences from the Baltic and Black Sea Circle Consortium for educational research. Discourse and Communication for Sustainable Education, 6, 21-29.

Salìte, I., Fjodorova, I., Meihami, H., Ivanova,O., Iliško, Dz., \& Gholami, J. (2019). JTES Approaches to Sustainability: Current Practices and New Perspectives for a More Sustainable World. Journal of Teacher Education for Sustainability, 21(2), $1-4$.

Salìte, I., Drelinga, E., Iliško, Dz., Oḷehnoviča, E., \& Zariņa, S. (2016). Sustainability from the transdisciplinary perspective: An action research strategy for continuing education program development. Journal of Teacher Education for Sustainability, $18(2), 135-152$. 
Srisaiphet, O. (2016). The effects of using a guidance activity on package with projectbased learning to develop problem solving skills of Mathayom Suksa III Students at Princess Chulabhorn's College, Satun in Satun Province. Academic Services Journal, Prince of Songkla University, 27(2), 61-68. Retrieved from http://dx.doi. org/10.14456/asj-psu.2016.21

Sunthonkanokpong, W., \& Murphy, E., (2019). Quality, equity, inclusion and lifelong learning in pre-service teacher education. Journal of Teacher Education for Sustainability, 21(2), 91-104.

Suwannoi, P. (2016). Problem-based learning: PBL. Retrieved from http://ph.kku.ac.th/ thai/images/file/km/pbl-he-58-1.pdf

UNESCO (2016). Happy schools! A framework for learner well-being in the AsiaPacific. UNESCO: Bangkok Office.

UNESCO (2020). Humanistic futures of learning. France: United Nations Educational, Scientific and Cultural Organization.

White, H. D. (1981). Interdisciplinary Teaching. Sanfrancisco: Jossey Bass.

Yavetza, B., Goldmanb, D., \& Pe'erc S. (2014). How do preservice teachers perceive 'environment' and its relevance to their area of teaching? Environmental Education Research, 20(3), 354-371.

Correspondence concerning this paper should be addressed to Yodsaphon Wanchana, Department of Education, Faculty of Social Sciences and Humanities, Mahidol University, Thailand. Email: yodsaphon.w@gmail.com 